\title{
Luiz Fernando de Lara Campos: uma pessoa admirável (1962/1999)
}

\author{
Geraldina Porto Witter ${ }^{1}$ \\ PUC-Campinas
}

Certamente, ao longo de uma longa vida profissional como docente e orientador é de se esperar que um professor universitário conheça muitas pessoas. Muitos são alunos. Alguns acabam em um obscuro ponto da memória, outros ocupam um espaço claro, definido. É entre os que assumem ou assumiram no passado o papel de orientandos que se encontram os alunos que melhor ficam conhecidos tanto com o profissionais quanto como pessoas pelo orientador.

Na enriquecedora atividade de orientação entre as muitas coisas que se aprende está a possibilidade de detectar e de investir em pessoas que farão uma carreira produtiva, enriquecedora, estabelecendo bases para mudança. São pessoas que estabelecerão diferença quer se ocupem com a atividade profissional, quer se envolvam com a vida administrativa, quer se dediquem a produzir conhecimentos, quer ainda cuidem da formação de outras pessoas. Entre as pessoas que a Autora teve a honra de orientar e ver evoluir rapidamente está Luiz Fernando de Lara Campos.

Para dar ao leitor uma melhor oportunidade de conhecer Luiz Fernando como pessoa, foram inseridos aqui alguns depoimentos colhidos junto aos que partilharam com ele momentos diversos da vida.

Seguem aqui arroladas algumas destas manifestações, as quais têm como denominador comum a admiração e o destaque de características pessoais marcantes de Luiz Fernando, capaz de doar-se integralmente para fazer seus alunos evoluírem, para ajudar alguém que a ele recorresse em busca de apoio; para envolver-se em uma colaboração dividindo tarefa ou mesmo para atender os que vinham em busca de sugestões.

Solicitada a escrever um breve texto sobre seu filho, assim se expressou sua mãe Sylvia M. de Lara Campos.

\section{História de um Vencedor}

Luiz Fernando nasceu às 6 horas da tarde, de parto normal, cercado de amor.

Herdou do sangue materno, a sensibilidade e a generosidade da alma italiana, que germinou na criança alegre e comunicativa.

O apelido "Cuca" foi dado por meu pai, que seria "Tuca" inicialmente, e acabou ficando Cuca.

O apego com os avós maternos foi desenvolvido desde muito cedo, protegendo e moldando suas primeiras qualidades. Cuca foi feliz na sua $1^{\mathrm{a}}$ infância.

Com a separação dos pais, ficou confuso e dividido, não pela separação em si, mas pela postura de todos que o cercavam. Passou a viver num tripé afetivo, que exigiu reformulações nos seus aproximados 8 anos. A disputa acirrada pelo afeto dele, chegou ao absurdo e ele conviveu e cresceu com o problema. Levado por mim a uma clínica de psicologia infantil, realizou testes e obteve acompanhamento adequado, vencendo os obstáculos.

Acredito que nesse momento, meu filho sentiu na pele, o valor de seu caminho.

Deus estava ao lado dele. Mudamos para os Jardins, onde ele conheceu seus melhores amigos.

Eram todos meninos e meninas bons, que com o tempo se ajudaram e cresceram unidos.

${ }^{1}$ Av. Pedroso de Morais, 144, apto. 302 - Pinheiros - 05420-000 - São Paulo, SP - Brasil. E-mail witter@uol.com.br 
Esses laços permaneceram até hoje.

Muito devo à "Turma", onde Cuca desenvolveu potencialidade positiva, convivendo com outras crianças, que tinham problemas familiares, talvez até mais sérios.

Recuperou a alegria.

Aos 9 anos sentava no chão, ao lado da minha cama, quando estávamos nos recolhendo, e perguntava sobre sexo, e outras dúvidas, questionando, com seriedade e desembaraço. Respondia todas as perguntas, replicava suas dúvidas, agradecida pela penumbra do quarto.

Dos meus filhos, foi o que mais dividiu sua intimidade, aberto e confiante.

O sorriso largo e franco de alegria era sua marca registrada, e muito me orgulho não ter permitido que o reprimissem, quando chorava de alegria ou de tristeza.

Aprendeu cedo a demonstrar suas emoções.

Como toda criança, teve problemas na escola, ciúmes das irmãs e muitas brigas.

Como adolescente teve crises de identidade, sentimentos ambivalentes. Eventualmente recorria ao apoio psicológico, cresceu.

Aos 14 anos iniciou sua carreira musical.

A seriedade e paixão pela música o levaram ao sucesso. Se expressava através da música e da dança, crescia sua alegria a cada conquista.

Contagiava a todos. A música o acompanhou por toda a vida.

Aos 17 ou 18 anos, começou a ganhar seu sustento, com som, em discotecas juvenis.

Fez nome, trabalhou nos melhores clubes da cidade de São Paulo. Deixou saudades, teve prestígio.

Teve facilidade no vestibular, e não era de estudar muito. Isso veio depois.

Abraçou com paixão a Psicologia e ao formar-se chorou emocionado, seus olhos brilhavam, estava orgulhoso e feliz pela vitória. Beijava todos nós.

Mas achou pouco. Dono de inteligência privilegiada, teve o "feeling" de decidir-se pela magistratura e com esforço, muito esforço fez sua pós-graduação.

Novamente Deus estava ao lado dele, quando o levou à cidade de Campinas, onde teve a oportunidade de conhecer "Geraldina". Ele falava assim. Ela gerou o equilíbrio da sua fé em si mesmo. Ao depositar seus olhos nele, teve a percepção do talento que ele trazia, valorizando o esforço a que ele se propunha.

Carente, sofrido sim, mas com uma força enorme de realizar, amar, sentir, ser feliz! Nascido na classe média, ao contrário do que se imagina, não foi fácil conquistar posições. Trabalhava à noite, estudava de dia, batalhou muito.

Meu legado, foi a determinação e persistência nos objetivos. A força do afeto que demos, exagerado com certeza, o ajudou.

Mas quis mais e com postura de adulto, seguro, fez seu mestrado na PUC-Campinas e na USP foi brilhante, ao defender sua tese de doutorado.

Já por volta dos 26 a 28 anos, pressentia que não viveria muito.

Foi um filho vibrante, carinhoso, íntegro e muito amigo. Dividíamos segredos e sonhos, muitos sonhos.

Num momento que foi só dele, antes de completar 29 anos, foi pelo mundo, realizar seus sonhos. E venceu!

Respeitei seu direito de escolha, por ter ensinado a ele, que tinha o direito de acertar ou não.

$\mathrm{O}$ amor pede renúncia. Mantive sufocada a esperança do seu retorno.

Não aconteceu.

Mas por tudo, em tudo o amei e amarei sempre.

"De peito aberto, com um sorriso largo, viveu intensamente. Lutou com coragem por seus objetivos. Amou com profunda ternura, semeando em todos a luz que dele emanava".

Por mais profunda que seja a dor

Por mais que chore tua ausência

Sinto a força de tua energia, que viva, devolve tua presença.

Valeu, filho. Valeu!

Sylvia 
O pai, Fernando de Lara Campos, optou por um bilhete de adeus ao filho, o qual é transcrito aqui.

\section{Luiz Fernando,}

Meu filho, foi um privilégio ter sido seu pai. Convivemos muito com altos e baixos. Foi comigo que você fez seu primeiro vôo de avião e foi pela primeira vez ao cinema ver um filme que não fosse desenho. Fui eu que lhe ensinei a guiar automóvel.

Até os 15/16 anos não era muito amigo dos estudos, mas depois pegou gosto, até demais para meu ver. Fez a faculdade e após esta, dezenas de cursos. Estava sempre estudando, ou pensando na sua profissão, até quando ia para minha casa na praia para descansar. Muitas vezes lhe disse que aproveitasse mais a vida e estudasse menos, mas você sempre respondia que mais tarde faria isso, mas o mais tarde não veio.

Você nos deixou muito cedo, quando tinha muito que fazer pela frente e sei que faria bem feito.

Você foi um filho irrepreensível, amoroso, carinhoso e companheiro do qual me orgulho. Foi também ótimo irmão para Ana Lúcia e Vera Cristina.

Todos os amavam muito e quando você se foi deixou em todos, sua esposa, mãe, avó, irmãs, e em mim seu pai, um grande vazio em nossas vidas.

Seu pai,

Fernando

Falando do irmão, Ana Lúcia retomou lembranças de uma convivência de longos anos.

Quando cheguei a este mundo, ele aqui já estava.

Me recebeu com um sorriso e nos tornamos amigos.

O tempo foi passando, e nós crescendo.

Às vezes nos amando, outras nos estapiando, mas sempre juntos, sempre amigos.

A infância e a adolescência, apesar dos problemas familiares (oriundos da separação de nossos pais), foi uma fase maravilhosa em nossas vidas.

Nos tornamos adultos e a vida nos levou a caminhos diferentes, mas a amizade e a cumplicidade sempre perduraram.

Cuca foi em busca de seus sonhos de uma forma extremamente objetiva, demonstrando uma determinação fora do comum.

O primeiro sonho alcançado foi a descoberta da Psicologia como profissão. Sua paixão por esta área transformou um rapaz que não gostava de estudar em um psicólogo dedicado. Esta foi a primeira grande transformação que aconteceu em sua vida.

Depois veio o mestrado, o doutorado... parecia que sua vontade de estudar não tinha fim... Era um grande prazer em sua vida ensinar e aprender sempre.

Enquanto isso, ele teve a sorte de achar uma pessoa especial como a Keli, e por ela se apaixonou. Apesar de virem de mundos diferentes, enfrentaram todos os problemas juntos e formaram um casal que se completava. Este foi o segundo sonho realizado... o de constituir uma família.

Viajar era uma obsessão, que agora começa a fazer sentido. A pressa em conhecer o mundo talvez tenha sido em razão dele sentir que seu tempo entre nós era curto.

Nestes 35 anos que convivemos, que fomos amigos, passamos problemas e, apesar de muitas vezes termos opiniões diferentes, sempre nos apoiamos. 
Cuca era meu melhor amigo, meu conselheiro, meu porto seguro.

Sim, era extremamente genioso, birrento, autoritário, mas nossa amizade era indestrutível.

Ai... um dia... simplesmente ele se foi. Deixou um enorme vazio em minha vida. Me sinto só. Me sinto desamparada.

Ainda busco o sentido da sua partida, mas não consigo achar, não consigo aceitar.

Dizem que o só o tempo nos conforta e isto tem sido minha esperança.

Se é verdade que um dia voltaremos a nos encontrar, não sei, mas tenho certeza que ele sempre será meu maior amigo, meu único irmão.

Sua outra irmã, Vera Cristina, assim se expressou:

Orgulho-me de ter sido irmã de uma pessoa tão determinada e capaz, realizava tudo com tanto êxito... Merece os aplausos de todos.

Certamente, a pessoa que se escolhe para partilhar a vida tem muito em comum, compartilha sonhos, com o tempo, é a pessoa que mais pode conhecer aquela com que divide a vida. Foi entre suas alunas que Luiz Femando encontrou aquela com quem partilharia sua vida mais íntima. Via em Keli uma pessoa esforçada, crítica, amorosa, desafiadora, com muitas características em comum com ele. Casaram e batalharam juntos para alcançar metas. O lar deles servia de apoio para amigos e de espaço para orientação de alunos, emprestava generosamente seus livros preciosos. Sua biblioteca crescia rapidamente e era de livre acesso para quantos o procuravam. Keli mantinha o equilíbrio em um lar onde o trabalho era também uma fonte de prazer, uma forma de partilhar idéias, valores, carinho. Tiveram nove anos para esta convivência tão próxima, tão cheia de planos, sonhos, mas também de realizações.

Keli assim se manifestou quando foi solicitada a falar sobre o esposo:

Quando, em 1990, conheci o Luiz Fernando, nunca imaginei que um dia o chamaria de "meu querido marido". Vínhamos de mundos muito diferentes, com histórias de vida muito diferentes, ele o professor e eu a aluna, só por isso já teríamos problemas de sobra (e tivemos), mas a paixão não utiliza-se da razão e acabamos por fazer destas diferenças, a marca de um grande amor, de uma enorme cumplicidade e de uma fórmula essencial para o relacionamento a dois, chamada companheirismo.

Falar do Luiz Fernando é falar de um homem forte, corajoso, de opiniões polêmicas, mas também alegre, com muitas paixões e que buscava novas descobertas. É lembrar de imagens intensas, é sentir muitas saudades, saudades do futuro, do que estava por vir.

O gosto pelas viagens era uma marca registrada de meu marido, além da querida coca-cola e das montanhas russas na Disney, onde se tornava uma verdadeira criança. Com ele era fácil conhecer o mundo, pois com sua cultura geral invejável, tornava-se um excelente guia turístico, papel que cumpria com orgulho e seriedade. Outra paixão sempre foi a música; como discotecário adorava proporcionar diversão aos amigos.

O companheirismo do nosso casamento dava margem a mútuas doações, como estar pronto para ler o trabalho do outro, opinar sobre uma palestra ou ler criticamente o livro que estava sendo terminado, ainda que isto custasse as nossas madrugadas.

Querido marido, como disse Rubem Alves, valeu a pena viver toda a minha vida só para poder ter vivido estes maravilhosos momentos ao seu lado. Obrigado por existir!!! 
Luiz Femando acompanhou a produção intelectual de Keli desde a graduação até sua pósgraduação. Entretanto, partiu antes da defesa de mestrado da esposa (20 de dezembro). Partiu, mas estava presente no texto, na lembrança dos presentes, na desenvoltura com que Keli passou pela sessão. Certamente, sentiu orgulho pela ex-aluna, pela esposa amada.

Entre 1997 e 1998, Luiz Fernando envolveu-se intensamente com a criação do desenvolvimento do Laboratório de Pesquisa em Psicologia - LAB Psi - na Universidade de São Francisco, do qual foi fundador e coordenador até seu falecimento.

O Laboratório estava funcionando sendo o envolvimento principal de seus integrantes com dois grandes projetos, financiados principalmente pela FAPESP. Um dos projetos tinha previsão de três anos, enfocava a área organizacional, contava com seis bolsistas de iniciação científica, três mestrandos e três docentes. O outro trabalhava com a questão da auto-eficácia na prática esportiva. Era coordenado por Luiz Femando que contava com a colaboração de um livre-docente da UNESP, Dr. Afonso A. Machado, com o mestre Femando C. Gouveia da USF e UMC, com dois bolsistas de iniciação científica e de Walmor de A. N. Largura.

O laboratório está bem organizado e estruturado e o trabalho em equipe era uma realidade já instituída e que deve dar continuidade à produção. É uma obra de cunho institucional. Criado para desenvolver o caldo cultural-científico-institucional, deve evoluir mantendo a proposta de oferecer condições não só de pesquisa para docentes, mas também para formação de recursos humanos (bolsistas de iniciação científica, mestrandos, doutorandos e outros profissionais interessados).

Foi entre seus ex-alunos que partilhavam a vida de produção do LAB Psi que se levantou o depoimento seguinte.

Conversando com um de seus ex-alunos e ex-orientando de iniciação científica, Walmor de A. N. Largura, enfocou-se como via Luiz Fernando como docente. A resposta foi a de que o via como um professor polêmico, capaz de mostrar ao aluno uma Psicologia viva, não estagnada, que fazia repensar a Psicologia, exigente mas capaz de ser um bom conselheiro. Estimulou-o a aperfeiçoar o inglês, a buscar os caminhos da pesquisa.

Luiz Fernando ofereceu-lhe a oportunidade de bolsa de iniciação científica e, sob sua orientação, Walmor recebeu primeiro uma bolsa do CNPq, depois que esta se encerrou recebeu outra da FAPESP. Assim contou com a orientação de Luiz Fernando de 1996 a 1998. Considera que era um exemplo de orientador; além de assessorar a pesquisa fazia com que o aluno procurasse aprimoramento lingüístico, se tomasse independente na busca e no uso da informação, aprendesse a usar a estatística. Era exigente, dava muita tarefa, fazia modelagem, cobrava, mas era generoso.

Walmor lembra que certa vez, procurando agradecer pelo que recebia, disse-lhe que não sabia como agradecer. Luiz Fernando respondeu algo como: "Faça valer a pena eu tê-lo orientado, produza e repasse a outros o que aprendeu." Lembra ainda seu envolvimento e preocupação em encaminhar seus bolsistas e outros orientandos para a pós-graduação e o empenho em que delineassem um plano de educação permanente - o que Walmor procura cumprir, seguindo os passos de produtor de seu professor.

Walmor participou de várias das atividades que estavam sendo desenvolvidas no LAB Psi e lembra a relevância do entusiasmo e da capacidade de organização de Luiz Fernando para a equipe e para sua produtividade.

Luiz Fernando foi, para a responsável pelo presente intertexto, aluno, orientando, colega e amigo. Em todos estes papéis foi uma pessoa singular. Como aluno era estimulante, sempre na 
frente, lendo mais do que o solicitado, trazendo para a classe a leitura de artigos recentes que tinham algo mais a acrescentar. Com ele em classe, o preparo da aula pedia estar mais do que em dia com as publicações sobre o tema. Era certo contar com uma colaboração ativa, instigante e desafiadora junto a colegas e docentes. A aula crescia, se enriquecia. Sua cobrança não se restringia ao nível e atualidade do conteúdo. Ficava nítida sua satisfação com estar aprendendo indiretamente, em muitas aulas, tecnologias diversas para a realização do processo ensinoaprendizagem. Era o primeiro a entregar os trabalhos e sempre da melhor qualidade. Trabalhava com prazer.

Como orientando foi uma pessoa atenciosa, carinhosa e com uma grande capacidade de trabalho. Não precisava ser cobrado porque estava sempre à frente no tempo e na qualidade. Era preciso "correr" para alcançá-lo. Era independente na busca de leituras, do que fazer e nas soluções de seus problemas de pesquisa. A orientação era um momento de partilhar conhecimentos, de repasse de experiência, rapidamente postos em uso por ele. Mais ainda, interessado no que os demais colegas-orientandos estavam fazendo sempre trazia a disposição de ajuda e colaborava com informações bibliográficas úteis.

Como colega nunca rejeitava trabalho, sempre arrumava tempo para dividir tarefas, apoiar realizações, estimular os companheiros. Não era apenas como colega docente que se podia contar com Luiz Fernando. No trabalho imenso subjacente aos eventos científicos, podia-se contar com integral apoio dele para todas as atividades, das mais ocultas às mais evidentes, das simples às complexas. Não falhava nunca. Cobrava de todos o mesmo empenho, o mesmo ritmo e nem todos suportavam a velocidade e a cobrança, preço que teve de pagar com discussões e outros inconvenientes. Mas todos reconheciam sua competência e força de trabalho.

O amigo Luiz Fernando sabia demonstrar seu interesse, sabia ouvir, sugerir, acompanhar as preocupações, os trabalhos, estimular, ajudar. Era a pessoa em quem sempre se podia confiar e com quem se podia contar em todas as horas. Nem mesmo se precisava formular o pedido de ajuda, ele a antecipava, intuindo a necessidade, buscando ser útil.

Era ótimo tê-lo como par no "colégio invisível", sempre atualizado, tinha informações e dados a partilhar. Foram momentos preciosos discutindo temas e problemas de ensino, de pesquisa, de Psicologia, do ser e do permitir ao outro também ser. Nos últimos meses, a troca vinha sendo bipartida: a universidade e os eventos científicos. Leituras e análises foram partilhadas, propostas delineadas, o tempo não permitiu sair do discurso para a prática. O ano 2000 seria um ano de grande atividade, de trabalhos mais partilhados, de esperanças de atuação entre instituições mais fortes e duradouras. O ano 2000 não contará com a presença de Luiz Fernando; partiu antes e muitos projetos ficaram truncados, outros seus colegas e colaboradores certamente irão levar avante.

O menino que nasceu em 29 de dezembro do ano de 1962 tinha pressa, tinha muito por fazer. Fez muito nos anos que passou neste mundo e vale aqui lembrar um pouco de seu envolvimento com a Psicologia, que escolheu como área de trabalho e de estudo. Trabalho e estudo eram inseparáveis para ele. Em 1986, obteve o título de psicólogo; em março de 1988 começou o mestrado na PUC-Campinas, obtendo o título em 20 de dezembro do ano seguinte; em 24 de novembro de 1994 obteve o título de doutor em Ciências pelo IPUSP. Exerceu atividade clínica, foi docente universitário (graduação, especialização, mestrado e doutorado). Nos poucos anos que teve para produzir (cerca de 10 anos) publicou muito: 22 artigos em periódicos científicos; 11 
artigos de divulgação; um livro; cinco capítulos de livros; 10 resenhas; 8 trabalhos completos em anais; 61 resumos em anais, além de participar ativamente do corpo editorial de quatro periódicos. Participou de 3 bancas de doutorado; 21 de mestrado; 4 de qualificação para o doutorado e 22 de qualificação de mestrado. Orientou 7 mestres, 8 bolsistas de iniciação científica e 14 trabalhos de conclusão de cursos. Fez 23 palestras e participou de 19 comissões técnico-científicas. Ficaram vários trabalhos no prelo que certamente sairão publicados em alguns meses.

Crítico, por vezes irreverente, usava dados e farta bibliografia de sustentação na exposição de seus argumentos. Criativo e irriquieto percorria campos diversos da Psicologia, com desenvoltura, dominando a bibliografia pertinente e atualizada. Leitor voraz, estava sempreem dia com os últimos textos publicados sobre o tema em que estava interessado. Impaciente, não aceitava que empenho similar não fosse feito por todos os profissionais, especialmente os docentes. Destes, cobrava mais pois eram modelos e como tal deveriam estar sempre em busca do saber atual, conhecer a história e pesquisar para poder levar aos alunos a ciência em pleno processo. Não aceitava desculpas e justificativas fáceis. O professor-pesquisador deve ser um exemplo, e ele sempre procurou ser um modelo. Certamente o foi, pois muitos de seus ex-alunos e ex-orientandos da graduação foram para a pós e além.

Luiz Fernando de Lara Campos teve morte violenta, em um acidente de carro, na estrada de Bragança Paulista, em 7 de outubro de 1999. A morte foi instantânea. Levou com ele muitos sonhos, projetos e realizações. Ficaram as saudades, as tristezas, os compromissos de dar continuidade, no que for possível, ao seu trabalho. Muito do que fez servirá de inspiração, de modelo e de sugestão a outros cientistas profissionais.

Adeus é apenas que uma triste parada no caminho. É uma certeza de que há pessoas que merecem afeto, admiração e confiança, para as quais se diz adeus, sabendo que sempre estarão presentes. Luiz Fernando, adeus. 